\title{
O uso de gêneros textuais no ensino de PLE na educação a distância
}

\author{
The use of textual texts in PLE teaching in distance education
}

\author{
Caroline Caputo \\ Universidade Federal do Sul da Bahia \\ Teixeira de Freitas, Bahia, Brasil.
}

Resumo: Este trabalho teve como objetivo verificar o uso das estratégias de aprendizagem utilizadas para elaboração de cursos na modalidade da educação à distância em função da prática com gêneros discursivos. $\mathrm{O}$ curso de Português para Estrangeiros na situação de Educação a Distância traz importantes implicações educacionais que poderão requerer dos professores e alunos maior atenção em relação à variável dos gêneros discursivos, bem como à necessidade de colaboração e intervenção no uso de estratégias de aprendizagem na educação à distância. A nossa abordagem traz como referencial teórico o letramento enquanto prática social que subsidia as análises referentes à leitura e à escrita e ao ensino-aprendizado em contexto situado de EaD. Para tanto, o objetivo do presente artigo é fazer uma discussão acerca da produção de material instrucional utilizado no ensino a distância. Nesse sentido, os multiletramentos subsidiam, enquanto ferramenta indispensável, o ensino e aprendizagem de línguas associado ao trabalho com gênero discursivo digital para o curso de Português para Estrangeiros na modalidade de Ensino a Distância.

Palavras-chave: Gêneros Discursivos, Português Para Estrangeiros, Educação A Distância.

Abstract: This work aimed to verify the use of the learning strategies used to elaborate courses in the distance education modality as a function of the discursive genre practice. The Portuguese for Foreigners course in the situation of Distance Education has important educational implications that may require teachers and students to pay more attention to the variable of the discursive genres, as well as the need for collaboration and intervention in the use of learning strategies in distance education. Our approach brings as theoretical references the literacy as a social practice that subsidizes the analysis regarding reading and writing and teaching-learning in a context of DE. To this end, the objective begins with a discussion about the production of instructional material used in distance learning. In this sense, the multiliteracy subsidize, as an indispensable tool, the teaching and learning of languages associated to the work with digital discursive gender for the course of Portuguese for Foreigners in the modality of Distance Education.

Keywords: Discursive Genres, Portuguese For Foreigners, Distance Education.

\section{INTRODUÇÃO}

\begin{abstract}
Não podemos ignorar que as redes de computação ainda deverão ser uma forma eficiente de construção social do conhecimento na medida em que se esvai a imagem do autor solitário e isolado produzindo textos oficias. (MARCUSCHI, 2000, p. 87).
\end{abstract}

Desde o início do século XX, alunos e professores se viram desafiados em virtude do desenvolvimento do processo de ensino-aprendizagem de línguas estrangeiras. Esses desafios ganharam novas dimensões com a disseminação das novas tecnologias de informação e de comunicação e, para os participantes do sistema educativo (professores e alunos) há uma urgência na necessidade de transformações para enfrentar essas novas abordagens educacionais. As tecnologias digitais têm apresentado e exigido cada vez mais habilidades para os novos modos de aprender como raciocínio rápido e flexível, domínio 
de várias línguas e o comando da informática. Neste contexto, a Educação a Distância (doravante EaD) cria espaços virtuais de colaboração e autonomia, a fim de oferecer oportunidades de atualização de capacidades de leitura e escrita virtual. Essa nova modalidade de ensino implica em novas formas de se comportar dos alunos e professores, como refletir sobre os novos meios de ensino e aprendizagem e ter autocontrole sobre as próprias atividades, considerados como decisões efetivas de situações de EaD.

A abordagem em EaD amortiza a distância interpessoal gerando assim interações entre alunos-professores e alunos-alunos (RIBEIRO, 2013). A partir dessa concepção, vários estudos têm evidenciado diferentes estratégias de ensino e aprendizagem de línguas ofertadas em cursos online, contribuindo para uma melhor orientação de aprendizagem em situações de uso e prática da língua-alvo. O uso da internet como espaço virtual de aprendizagem propicia ainda mais a prática de ensino com a utilização de vários gêneros discursivos como, por exemplo: discussão em fóruns, leitura e escrita de e-mails, de receitas, diálogos, vídeo-aulas, entre outros, evidenciando o predomínio de interações entre interlocutores para o desenvolvimento de capacidades de pensar, escrever e ler utilizando os novos recursos linguísticos virtuais e, assim, potencializar áreas cognitivas criando, portanto variadas formas de uso social e cultural da língua-alvo. Dessa forma, atividades com gêneros discursivos são instrumentos que proporcionam o agir discursivamente nas diversas esferas sociais, como confirma Marcuschi (2005), "a comunicação verbal só é possível por algum gênero textual". Assim, o trabalho com gêneros possibilita que os alunos participem de situações reais de uso da linguagem, desenvolvendo assim a comunicação oral e escrita mesmo estando em ambientes EaD.

Para Almeida Filho (2011, p. 54), "as línguas não foram criadas para serem primordialmente ensinadas quanto a sua forma, mas adquirida em e para o uso", assim os gêneros discursivos propiciam uma dimensão de movimento da língua-alvo. Nesse contexto, o ensino de Língua Portuguesa como Língua Estrangeira (doravante PLE) é considerado uma empreitada diversificadora da compreensão do Português e das culturas associadas a essa língua. O ensino de PLE reúne, portanto conhecimentos sobre a multiplicidade de usos desse idioma. Observa-se, assim, que o ensino e aprendizagem da língua portuguesa para estrangeiros proveem de uma competência comunicativa transformada da competência já abrigada em outra língua e que depende da interação dos alunos-alunos e alunos-professores. Assim, o ensino de PLE é considerado, então, como um lugar de abrangente intercâmbio social e circulação da língua portuguesa.

Nesse sentido, buscando contribuir para uma reflexão sobre o processo de ensino e aprendizagem na Educação a Distância para cursos de Português para Estrangeiros, este trabalho tem como objetivo geral analisar as estratégias cognitivas e metacognitivas de aprendizagem utilizadas por professores e tutores na modalidade $\mathrm{EaD}$ e, como objetivo específico, verificar se há diferenças no uso de estratégias das atividades utilizando variados gêneros discursivos em tarefas interativas online. 


\section{GÊNEROS TEXTUAIS E A PERSPECTIVA DE AÇÃO PEDAGÓGICA}

Os documentos educacionais oficiais para o ensino de LE, como os PCNs (1998), orientam as ações de professores e alunos para se engajarem em priorizar a comunicação na LE, apontando essa prática para a necessidade de se trabalhar com gêneros textuais em vista a contribuir para consolidar as atividades comunicativas. Portanto, a prática de produção textual (leitura e escrita) é vista como uma atividade excelente para trabalhar aspectos léxico-sistêmicos da língua-alvo em relação da função social. Corroborando com Bazerman (2006) ao afirmar que escrever é uma atividade social, observamos que as atividades de produção textual buscam o desenvolvimento dos alunos em relação ao uso das estruturas gramaticais e do vocábulo da língua-alvo. Para ele, os gêneros discursivos organizam nossas vidas. Bazerman (2006) também afirma que há textos e atividades sociais que são sistemas bem organizados e articulados, os quais circulam de forma previsível e nos afetam a todo instante. Bazerman compreende os gêneros como fenômenos de reconhecimento psicossocial. Trata-os como formas tipificadas que tipificam ações sociais, como, por exemplo, certidões de casamento ou contratos de aluguel que afetam e influenciam as ações, direitos e deveres das pessoas.

Segundo Bazerman, os gêneros discursivos também contribuem para a construção de identidades sociais. Para ele, a produção de um conjunto de gêneros dentro de um sistema de atividades permite o desenvolvimento de identidades social, como também formas de vida coletivas próprias daquele espaço-discursivo, como nas atividades interativas na modalidade EaD.

Assim, o desenvolvimento do conhecimento sobre gêneros textuais pode contribuir como um intrínseco instrumento de comunicação e ensino por serem ferramentas necessárias para agirmos discursivamente nas diversas esferas sociais. Nesse sentido, o ensino de PLE, com gêneros textuais através da visão sociointeracionista, possibilita aos alunos participarem de situações reais de uso da língua portuguesa e desenvolverem assim a comunicação oral e escrita. Seguindo essa ideia, Vygotsky (1996) propõe o desenvolvimento cognitivo por meio da interação social, em que existe há troca de experiências e ideias.

Seguindo essa abordagem, o professor de PLE tem o papel de orientar e planejar situações que propiciem a simulação de práticas sociais para instrumentalizar os alunos a agirem adequadamente com a linguagem em uma situação de comunicação real, sendo, portanto o trabalho com gêneros textuais uma prática que lida com a língua em seus diversos usos no dia a dia. Atentando para o ensino de LE por meio de gêneros textuais, Cristovão (2005) confirma que o professor deve analisar o contexto em que serão desenvolvidas as capacidades linguísticas dos alunos assim como as capacidades que precisam para desenvolver a leitura e escrita de textos do gênero. Dell'Isola (2007) corrobora essa abordagem afirmando que o ambiente de ensino de PLE se torna um laboratório para experimentar e praticar a linguagem em situações de interações simuladas de comunicação transformando os alunos em produtores de textos capazes de escrever com propósitos reais de comunicação, a fim de se tornarem agentes da própria escrita. Assim, o ensino através de gêneros discursivos desenvolve as ações de pensamento e 
intenções dos alunos causando efeito desejado como interlocutores na atuação sociodiscursiva não se tornando, portanto simples produtores textuais.

É importante ressaltar que para Marcushi (2005, p. 20) os gêneros textuais são fenômenos históricos intrinsecamente ligados à vida cultural e social, sendo, dessa forma, de extrema relevância a constituição da função comunicativa, cognitiva e institucional em que se desenvolvem, de acordo com suas peculiaridades linguísticas, pois eles surgem e se modificam constantemente, uma vez que estamos mediante as novas tecnologias nas últimas décadas, que nos impulsionam a cada vez mais usá-las nas atividades comunicativas cotidianas.

Por agirmos no mundo social por meio da linguagem, Bakhtin e Bronckart (2003) concordam que o texto corresponde a uma unidade comunicativa ou interativa global por apresentar particularizações de situações de interação na qual são produzidos e nas condições sócio históricas de sua produção. Para Bakhtin, a interação verbal é uma prática social que tem na língua a sua realidade material. Dessa forma, a firma que "a língua penetra na vida através dos enunciados concretos que a realizam.” (BAKHTIN, 2003, p. 282) de mesma forma que a vida penetra nela também. Para o autor, toda a linguagem é dialógica, por ter uma relação imediata com o outro. Ao afirmar "A vida é dialógica por natureza. Viver significa participar de um diálogo: interrogar, ouvir, responder, concordar, etc" (BAKHTIN, 2003, p. 348).

É importante considerar que essa interação verbal não se dá por meio de uma passividade, e sim entre uma troca de realidade sócio históricas de seus interlocutores uma vez que o falante, o ouvinte e o tema do discurso são fatores importantes para esse processo. Para o autor:

O discurso é como o "cenário" de um certo acontecimento. A compreensão viva do sentido global da palavra deve reproduzir esse acontecimento que é a relação recíproca dos locutores, ela deve "encená-la", se se pode dizer; aquele que decifra o sentido assume o papel de ouvinte; e, para sustentá-lo, deve igualmente compreender a posição dos outros participantes. (BAKHTIN, 1926, p. 199).

Observa-se a perspectiva acional (LOUSADO, 2012) dos gêneros textuais por conterem atividades de compreensão, observação e escrita e interação da prática nas aulas de LE. Assim, o trabalho com gêneros discursivos em cursos de PLE contribui para o ensino em uma perspectiva sociointeracionistas e de letramento crítico.

Dessa forma, o material didático é visto como um gênero discursivo da esfera escolar e permitindo que o aprendiz atue no mundo usando a língua-alvo, assim é necessário que os conteúdos temáticos propostos propiciem o engajamento discursivo do aluno no domínio social. O desenvolvimento do letramento crítico que os materiais didáticos apresentam pode ser viabilizado em trabalhos com gêneros discursivos, pois representam e constroem experiências da realidade social.

Com base nessas observações, o material didático do curso de PLE pode ser identificado como um texto que articula interações texto-leitor, construindo relações sociais e de poder, assim como identificando vozes discursivas. Assim, o trabalho com gêneros discursivos em materiais didáticos no ambiente EaD implica tornar o ensino da 
linguagem a forma de ação social, viabilizando formas de se agir no mundo através do uso da língua-alvo.

\section{MULTIMODALIDADE E INTERATIVIDADE DOS GÊNEROS TEXTUAIS NO AMBIENTE EAD}

A web possibilitou o surgimento de textos com múltiplas semioses, coexistindo com uma linguagem digital que privilegia modalidades variadas da escrita. Essa nova modalidade transforma modos de representação cultural. Essas mudanças significativas confirmam um novo tipo de texto que se apresenta recorrente nos usos sociais: o texto multimodal. A Teoria do Multiletramento (SEBER, 2004; KALANTZIS e COPE, 2012) possibilita a compreensão dos novos modos de representação da linguagem verbal e nãoverbal (BALADELLI, 2011), sendo o texto multimodal fragmentado e não-linear, cujo significado se realiza por códigos semióticos variados (KRESS \& VAN LEEUWEN, 1996).

A transposição da habilidade de leitura e escrita do texto impresso para o ambiente virtual conduz a uma transformação do leitor, que se torna coautor de suas produções. Pelo hibridismo do texto eletrônico, devido a códigos semióticos e hipertextos que interligam a leituras e escritas variadas, faz-se necessário que o letramento crítico se imprima nas esferas pedagógicas. $\mathrm{Na}$ web, o leitor/navegador é conduzido a um universo multisemiótico, exigindo então um letramento digital sendo capaz de interagir e compreender o uso da linguagem mediada pela tecnologia atual. Assim, uma nova modalidade de ensino surge na qual não necessita da presença do professor face a face, pois a interação do professor e do aluno pode ser mediada virtualmente envolvendo como sujeitos ativos no ensino/aprendizagem de LE a triangulação professor/aluno/quadro interativo.

Surge então, uma nova modelagem de ensino/aprendizagem através do domínio de textos multimodais tendo como suporte a mídia virtual. Corporificada ao ambiente virtual, o texto multimodal é arraigado de gêneros digitais (BRITO e SAMPAIO, 2013) que misturam sons, imagens e palavras, como blogs, twitter, email, MSN, entre outros, sempre com caminhos para uma nova informação como hipertextos. Sendo o texto no ambiente virtual aberto, o letramento digital produzirá "hiperleitores" por conscientizar e orientar os alunos/navegadores a participar com autonomia e colaboração na cadeia de aprendizagem constante que a interação comunicativa permeada pela linguagem no ambiente virtual pode oferecer. Dessa forma, uma pluralidade de gêneros discursivos efetivos na interatividade online por apresentarem o uso real da linguagem, como confirma Dias: "que a leitura é um processo interativo entre leitores, textos e contexto”. (DIAS, 2011, p. 899). ${ }^{1}$ Dias observa que a compreensão da leitura é compreendida a partir da interpretação de textos multimodais que combinam diferentes códigos semióticos.

1 "that reading is an interactive process between readers, texts and context" (DIAS, 2011, p. 899) 
Nesse contexto, o papel do professor deve estar situado nas novas abordagens de aprendizagem que aguçam a troca de saberes, a interação linguística e simbólica e a colaboração efetiva e instantânea. Sendo assim, o professor se tornar um pesquisador permanente de novas formas de ensinar a fim de apoiar os alunos nos processos de aprendizagem, adaptando suas estratégias de ensino para auxiliar o desenvolvimento de aprendizagens. Assim, nas aulas de língua estrangeira em cursos online, o professor pode explorar o trabalho com recursos digitais usando a língua escritas nos variados gêneros textuais, baseados em teorias de leitura e abordando estratégias diferentes exigidas pelos vários gêneros digitais.

Os objetos de ensino e aprendizagem de línguas estrangeiras em cursos online disponibilizam várias possibilidades de práticas do uso da língua. Cabe ao aluno, o preparo adequado para lidar com essas novas práticas apoiadas aos recursos dos objetos de aprendizagem, principalmente porque cada momento da situação de aprendizagem deve ser adaptado ao ambiente virtual, pois exige estratégias diferentes. Cursos online são excelentes ambientes para o meio de comunicação, sendo possível destacar que os gêneros oriundos de ambientes multimídia, caracterizados por criar, manipular, armazenar e pesquisar conteúdos diversos, como imagem e som, são repletos de interação social.

Em suma, o letramento digital agrega situações de comunicação ainda pouco exploradas em cursos online de LE e com isso novas formas de interação são criadas por meio dos recursos digitais e textos eletrônicos que se constituem como os gêneros textuais digitais. As práticas dos gêneros digitais envolvem processos cognitivos múltiplos, nos quais o leitor percebe e reflete o conjunto dos componentes textuais e simbólicos que compõem o texto, desencadeando um novo processo de leitura no qual a tela concretiza o texto, e o aluno/leitor tem a noção de todos os aspectos semióticos do texto.

\section{TEORIA NA PRÁTICA: ENSINO DE PLE AUXILIADO PELA EDUCAÇÃO À DISTÂNCIA}

À medida que a novas abordagens de ensino evoluem também há a necessidade de conhecer efetivamente essas mudanças, pois os novos objetos de estudo também mudam. É crucial que se acompanhe esse processo estudando, aprimorando nossos conhecimentos e, principalmente, desenvolvendo as concepções de ensino e ferramentas pedagógicas, porque as mudanças atuais também implicam mudanças nas formas de ensino. Nos cursos de PLE em EaD, as atividades pedagógicas podem e devem estar relacionadas aos novos gêneros textuais, juntamente nas concepções de ensino em que o letramento digital está envolvido, pois os alunos precisam encarar o desafio do aprendizado e do uso das tecnologias educacionais, além de se prepararem para a nova realidade linguística, aprendendo a lidar colaborativamente e com autonomia ao usar a língua-alvo. Dessa forma, o aluno não só interagirá com o professor e os outros alunos, mas também com o computador, os programas e a Internet. Assim, ele desenvolverá habilidades de leitura e escrita bastante seletivas no processo de aprendizagem.

$\mathrm{Na}$ prática de ensino em EaD, vários gêneros são trabalhados e apresentaremos uma análise da prática desenvolvida pela professora Carolina Caputo no setor de EaD da 
Universidade Federal de Viçosa (UFV) no ano de 2012 que foi aplicado nas aulas com os alunos estrangeiros/intercambistas que pretendiam cursar disciplinas de graduação ou pós administradas em língua portuguesa. Por serem variantes do mesmo gênero, cartas e bilhetes foram explorados. Nas atividades online, a professora faz o uso da estrutura do e-mail para desenvolver alguns conteúdos gramaticais, estimular a produção textual, exercitando variantes linguísticas específicas desse gênero textual, além da adequação de uso e tipos de texto, como resumos, geralmente utilizados nos e-mails, por serem textos breves. No curso online os alunos publicam/postam suas produções e em seguida os outros alunos colaboram com a aprendizagem gerando respostas. Essa participação efetiva motiva os alunos a se tornarem praticantes da língua-alvo. No caso do curso online de PLE, como o público alvo são os alunos estrangeiros, até o layout das atividades são explicados durante as aulas para que possam compreender de forma prática o uso dessas ferramentas de ensino de PLE no formato em que é apresentado na prática cultural da língua. Esse exemplo pode ser observado no anexo 1, que mostra a aula 5 do curso de PLE, que desenvolve o tema "Falando sobre assuntos polêmicos: Estereótipos".

Além de e-mails e cartas, o curso online também pode explorar os gêneros textuais blogs e redes sociais, que são ótimos sites para a prática da escrita colaborativa. Os benefícios dessas ferramentas destacam-se no enriquecimento das discussões, o aumento do interesse dos alunos para pesquisas, motivação dos alunos e, principalmente, a interdisciplinaridade. Nos blogs, o professor pode avaliar a compreensão do aluno, sua capacidade de sintetização, domínio e análise de conteúdos e, também, a interação entre professor/aluno e aluno/aluno. Tem-se também a possibilidade de acrescentar às interações variados códigos semióticos que enriquecem a comunicação interativa dos cursos online, como vídeo e áudios.

Como o ensino de PLE privilegia o desenvolvimento da língua atrelada ao uso prático com a cultura brasileira, o curso online de PLE apresenta uma seção distinta para a compreensão de aspectos culturais da língua portuguesa. Tem-se nessas seções a oportunidade de assistir vídeos, ouvir áudios de diálogos ou músicas e analisar imagens que representam aspectos geográficos e históricos do Brasil, levando os alunos a interagirem e produzirem lexicamente diferentes gêneros textuais como cartões postais de lugares específicos do Brasil, convites de viagem por e-mails, discussões em chats ou no blog.

Assim, o trabalho em ambientes digitais nos cursos online de PLE exige do professor o uso consciente de práticas próprias da interpretação intercultural, para que haja interação e colaboração na leitura hipertextual. Coover (1992, p. 1) afirma que "o hipertexto apresenta uma tecnologia radicalmente divergente, interativa e polifônica, favorecendo a pluralidade de discursos sobre o enunciado definitivo e libertando o leitor da dominação do autor". Esta é a habilidade primordial para que o professor, ao elaborar as orientações e textos didáticos, observe o sentido de promover o desenvolvimento, pelo aluno, das habilidades pressupostas pela leitura e produção de interações em um ambiente intercultural.

Com os gêneros textuais mencionados, e-mails, blogs, chats e textos em redes sociais, o curso online de PLE da UFV desenvolve muito a escrita, inclusive pode explorar 
atividades que visam atividades de audição para que posteriormente os alunos produzam diálogos e textos, sendo formas de construção textual comuns à escrita digital. Percebese, pois, que os gêneros textuais digitais permitem amplas formas de atividades que ampliam o aprendizado da língua portuguesa no ambiente EaD.

O material impresso usado em EaD ainda apresenta-se como instrumento didático importante no processo de mediação entre alunos e professores. Acostumados a adotar livros didáticos para apoiar as aulas, os professores de cursos online consideram os desafios da $\mathrm{EaD}$ ao descobrirem-se como produtores de materiais didáticos que precisam desenvolver competências comunicativas na língua-alvo e priorizar uma abordagem dialógica na produção textual.

\section{CONSIDERAÇÕES FINAIS}

A era do avanço tecnológico associado à educação tem feito da internet uma ferramenta que vislumbra uma era de oportunidades quando o assunto é tempo e distância. No curso de PLE da EaD oferecido pela UFV a alunos intercambistas é um dos problemas solucionados, pois desvincula a necessidade presencial, tendo o aluno a oportunidade de aprender a língua portuguesa em seu país de origem e/ou aprender a língua antes de vir para o Brasil. Outro aspecto de suma importância é que a educação a distância possibilita que o aluno gerencie seu tempo de estudo e dedicação ao novo conhecimento. No curso, há traços de educação presencial, pois faz parte das atividades o quadro/link representacional do professor através de chats e do aluno em avaliações para identificar o ensino e aprendizagem da língua-alvo.

Com base nessas discussões, esse trabalho visa a descrever um novo perfil das atividades de cursos online de PLE, capaz de promover o desenvolvimento das habilidades pressupostas pelos alunos estrangeiros para a leitura proficiente de gêneros discursivos digitais sendo ajustados a aspectos culturais da língua portuguesa. Para tanto, essa investigação resulta na organização de elementos teórico-metodológicos que possam instrumentalizar os professores-organizadores de cursos em $\mathrm{EaD}$ para uma maior apreciação das atividades/estratégias de leitura no formato hipertextual a fim de que haja uma maior compreensão da língua pelos alunos de PLE.

Em suma, para a elaboração de cursos online de PLE é preciso saber usar o poder da tecnologia de forma positiva a fim de valorizar a interação dos alunos estrangeiros que estão em imersão ou não na língua-alvo, propiciando o diálogo, a troca, a construção coletiva de aspectos linguísticos e culturais, na qual os professores juntamente com os alunos assumem novos papeis no processo de ensino-aprendizagem, posições de parceria colaborativa. Desta forma, o trabalho com gêneros discursivos orienta os alunos e professores para alcancem uma maior interação com a língua e seus aspectos culturais focando assim na autonomia do aluno conduzido a um estimulo instigado pelos gêneros discursivos a buscar um comprometimento com a construção do conhecimento na colaboração intercultural no ambiente EaD. 


\section{REFERÊNCIAS}

ALMEIDA FILHO, J. C. P. Ensinar uma nova língua para aquisição. In: Fundamentos de Abordagem e Formação no Ensino de PLE e de outras linguas. Campinas, SP: Pontes Editores, 2011.

BAKTHIN, M. Estética da criação verbal. 4. ed. São Paulo: Martins Fontes, 2003.

M.; VOLOSHINOV, V. N.. Discurso na vida e discurso na arte: sobre a poética sociológica. Tradução, para uso didático, de C. A. Faraco e C. Tezza. 1993[1926].

BALADELLI, Ana Paula D. Hipertexto e multiletramento: revistando conceitos. Nilópolis, RJ: 2011.

BAZERMAN, C. Gêneros, agência e escrita. Organização de Judith C. Hoffnagel e Ângela P. Dionísio. São Paulo: Cortez, 2006.

BRITO, F. F. V \& SAMPAIO, M. L. P. Gêneros Digitais: A Multimodalidade ressignificando o ler/escrever. Santa Cruz do Sul, 2013.

BRONCKART, J. P. Atividade de linguagem, textos e discursos: por um interacionismo sócio-discursivo. São Paulo: EDUC, 2003.

CRISTÓVÂO, V. L. L. "Aprendendo a planificar o próprio trabalho: genros textuais na formação de professores de língua estrangeira", In: CRISTÓVÂO, V. L. L. e NASCIMENTO, E. L. (orgs.) Gêneros textuais: teoria e prática II. Palmas e União da Vitória: Kayagangue, 2005, pp. 153-162.

COOVER, Robert. The End of Books. New York Times Book Review, 21, p. 1, June 1992.

DELL’ISOLA, R. L. P. Retextualização de gêneros escritos. Rio de Janeiro: Lucerna, 2007.

DIAS, Reinildes. Concepts Maps powered by computer software: a strategy for enhancing Reading comprehension in English for Specific Purposes. Belo Horizonte, 2011.

KALANTZIS, M. \& COPE, B. Literacies. Australia: Cambridge University Press, 2012.

LOUSADO, E. G. Gêneros textuais e perspectiva acional no ensino do francês como língua estrangeira: prescrições e instrumentos para o agir de alunos e professores. In: DIAS, R. \& DELL'ISOLA, R. L. P. Gêneros Textuais: Teoria e prática de ensino em LE, Campinas, SP: Mercado de Letras, 2012.

MARCUSCHI, L. A. "Gêneros Textuais: definição e funcionalidade", In: DIONISIO, A. P.; MACHADO, A. R. e BEZERRA, M. A. (orgs) Gêneros Textuais e Ensino. Rio de Janeiro: Editora Lucerna, 2002 [2005], pp. 19-36.

RIBEIRO, Pollyanne B. O outro extremo do uso da linguagem: efeitos representacionais na EAD. In: ARAÚJO, J. \& ARAÚJO, N. EAD em Tela: Docência, Ensino e Ferramentas Digitais. Campinas, SP: Pontes Editores, 2013, p. $11-24$.

SELBER, S. A. Multiliteracies for a Digital Age. Carbondale: Southern Illinois University Press, 2004.

VYGOTSKY, L.S. A formacão social da mente: o desenvolvimento dos processos psicológicos superiores. 5. ed. São Paulo (Brasil): Martins Fontes, 1996. 
KRESS, G. \& VAN LEEUWEN. Reading images: the grammar of visual design. London; New York: Routledge, 1996.

Recebido em: 22/05/2018

Aprovado em: 15/08/2018

Publicado em: 31/12/2018 